DOI: 10.21892/978-958-5547-66-7.6

\title{
6. Análisis de la carga de la prueba de la pérdida de oportunidad en la responsabilidad civil médica en Colombia
}

Juan Carlos Ramos Santamaría ${ }^{8}$

\section{Introducción}

El presente estudio denominado "Análisis de la carga de la prueba de la perdida de oportunidad en la responsabilidad civil médica en Colombia" procura ser el resultado de la profundización sobre la carga de la prueba, en un campo tan complicado como son las acciones judiciales derivadas de la responsabilidad civil médica, aunando la teoría de la perdida de oportunidad para el paciente como un factor que puede determinar una mala praxis.

La actividad medica desde el punto de vista físico es esencialmente riesgosa, no solo porque generalmente se utilizan aparatos peligrosos, sino porque el organismo del paciente está sometido a enormes riesgos, por el simple hecho de la actividad del médico al efectuar el tratamiento (Jaramillo, 2010).

El ámbito de la salud, con todos sus componentes, se ha convertido en una bandera para las sociedades modernas. El derecho a la salud (Const., 1991, art. 49), se ha catalogado dentro de los derechos fundamentales (Const. Esp., 1978, art. 43) y se ha promulgado con tanta fuerza que uno de sus rasgos característicos es la imposición de organización y de prestaciones fácticas a los poderes públicos.

El progreso de la ciencia médico quirúrgica ha sido impulsado por el hecho, fácilmente constatable, que la técnica ha invadido la medicina, concediendo avances extraordinarios en los tiempos actuales: órganos del

8 Abogado de la Universidad de San Buenaventura. Especialista en Seguros de la Universidad Externado de Colombia. Especialista en Derecho Contencioso Administrativo de la Universidad Externado de Colombia. Máster en Seguros y Gerencia de Riesgo de la Universidad Pontificia de Salamanca, España. 
Análisis de la carga de la prueba de la pérdida de oportunidad en la responsabilidad civil médica en Colombia

cuerpo humano son extraídos, manipulados y trasplantados de un cuerpo a otro con asombrosa evolución técnica; las técnicas de la reproducción asistida, las modernas técnicas de radiodiagnósticos, los rayos gamma que pueden superar al bisturí, el proyecto genoma humano (Costales, 1995).

Como lo pregona la doctora Mónica Lucía Fernández Muñoz en su tesis doctoral denominada "La responsabilidad Médica, Problemas actuales" (Feger, 2002), en ella manifiesta que:

El ejercicio de la medicina se ha transformado con el pasar del tiempo. En la actualidad, la relación médico-paciente, personalizada en un tiempo, ha sido llevada a su mínima expresión y ha sido transformada por una relación despersonalizada. Hoy en día, es más común encontrar pacientes que por una negligencia no atribuible al personal médico, sino a la estructura hospitalaria, pierdan la vida o se encuentren ante complicaciones no justificables.

El ejercicio de la ciencia médica no es exacto y su mismo ejercicio entraña riesgos. Sin embargo, la responsabilidad civil médica, sigue el esquema general de la responsabilidad civil, por ello, quien pretende sean resarcidos los daños o perjuicios que se le han ocasionado al paciente o sus familiares, deberá acreditar ante el juzgador los mismos elementos de esta, tales como el daño, el hecho generador o culpa y la relación de causalidad; obligando al paciente, familiares o perjudicados y víctima a la carga de la prueba.

Ahora bien, el desarrollo de las nuevas jurisprudencias, el análisis causal (que se llamará ahora imputación normativa) implicará agotar dos pasos: el primero orientado a identificar el universo de causas naturales que dieron lugar al daño (todas las causas que fácticamente incidieron) y el segundo, en el que el operador deberá seleccionar cuál de tales causas le es jurídica o normativamente imputable al agente dañador, si la hubiere (lo que los sistemas europeos denominan el Scope of Liability).

El problema jurídico en todos los casos de responsabilidad médica es determinar si las actuaciones realizadas en desarrollo de la atención que se brindó a la víctima guardan o no conformidad con la lex artis, situación que no es pacífica por las condiciones mismas del paciente y sus familiares, quienes carecen de los conocimientos técnicos y científicos que les permitan 
tener esas valoraciones de una forma certera, sin que haya lugar a especular si con la utilización de unos procedimientos distintos se hubiera evitado la afectación sufrida por el paciente o conseguido otro resultado, precisó la Corte Suprema.

Los pronunciamientos sobre la carga de la prueba en la responsabilidad civil médica han ido divagando en el tiempo, cambiando posturas jurisprudenciales y doctrinales, fluctuando entre la responsabilidad objetiva y la responsabilidad subjetiva, incidiendo de forma directa en la obligación probatoria, a quien le corresponde probar los supuestos de hechos que se reclaman, esto determina que la carga probatoria le corresponde al paciente o sus familiares; es a ellos a quien les corresponde el onus probandi para este tipo de procesos.

Cuando nos enfrentamos a responsabilidades derivadas de una mala praxis médica, conforme a la regla general probatoria, la carga de la prueba radica en cabeza del paciente o sus familiares; sin embargo, de cara a la práctica judicial y a la obtención de sentencias favorables, estamos sentados en un campo probatorio donde es difícil acreditar el nexo de causalidad entre el comportamiento médico negligente y el daño sufrido por el paciente, aparece dentro de ese lugar inhóspito la doctrina de la pérdida de oportunidad, que nos permite analizar la probabilidad significativa de que el evento dañoso no hubiera tenido lugar de haberse dado la conducta debida, que dicha negligencia privó al paciente de oportunidades de curación o supervivencia que deben ser reparadas o indemnizadas.

La doctrina de la pérdida de oportunidad pretende demostrar el incumplimiento de una obligación emanada del contrato de atención médica, que ese incumplimiento genera en el paciente la imposibilidad de que su organismo reaccione de forma favorable ante un tratamiento o limita las mismas probabilidades de beneficios del tratamiento médico, es a su vez considerado como un perjuicio autónomo, que debe ser reparado de forma independiente del daño final, situación que ha sido aclarada por las altas cortes, en particular por la Sección Tercera el Consejo de Estado.

Este tipo de daño surge cuando la actuación del personal médico o instituciones reducen la expectativa que pudo haber tenido la víctima de padecer una pérdida menor. Ello se evidencia cuando no es posible establecer un nexo causal entre la actuación del personal médico o 
instituciones y la afectación concreta que sufre el demandante, a través de las pruebas arrimadas al proceso.

Sin embargo, la teoría es más sencilla que la práctica, los demandantes, pacientes, o sus familias, están obligados a probar cómo esa omisión específica reduce significativamente la expectativa que pudo haber tenido la víctima de padecer una pérdida menor, trasladándose al campo probabilístico. Este trabajo presenta un análisis sobre la carga de la prueba necesaria que permita llevar al juzgador la certeza sobre de la pérdida de oportunidad en el campo de la responsabilidad médica.

\section{Cuestiones previas de responsabilidad médica}

\subsection{La responsabilidad civil médica}

En este aparte, ubicaremos jurídicamente la responsabilidad del galeno cuando en el ejercicio de su actividad ocasiona perjuicios al paciente o a sus familiares, distinguiendo entre los daños causados por el médico, sin que este haya realizado un acto médico que pueda eventualmente catalogarse como defectuoso o cuando son daños causados por actos médicos defectuoso, exponiendo algunos conceptos básicos.

\subsection{Conceptos básicos}

En este apartado se hace alusión a conceptos básicos que ayudarán a comprender el contexto en el que se desarrolla el presente trabajo.

\subsubsection{Responsabilidad jurídica}

El concepto de responsabilidad, posee diversas acepciones, como aspecto general el concepto de responsabilidad proviene del latín responsum, que es una forma latina del verbo responde (responder), habilidad (habilidad) (Larrañaga, 1996). La real academia española, lo menciona como la obligación moral que resulta del posible error cometido por un sujeto en un asunto determinado; la obligación de resarcir o reparar las consecuencias de un hecho o acto.

En el ámbito jurídico, el término responsabilidad jurídica proviene del latín spondere, prometer, que al anteponer el prefijo re, adquiere el 
significado de repetición o reciprocidad. La palabra responsabilidad, heredada de Inglaterra, solo empieza a usarse en sentido jurídico en Francia en el siglo XVIII cuando se incluye en el diccionario Crítico de Necker y Feraud de 1789 (Facio, 1981). De acuerdo al Diccionario de la Real Academia, la acepción de responsabilidad es: "deuda u obligación de reparar y satisfacer, por sí o por otro, a consecuencia de un delito, de una culpa o de otra causa legal". Diferentes autores manejan el tema de la responsabilidad jurídica y dan su percepción sobre el tema, para el Doctor Pablo Larrañaga en su fragmento de la tesis doctoral dirigida por el profesor Manuel Atienza, con el título "El concepto de responsabilidad en la teoría del derecho contemporáneo", expuesta en Fontamara, México, D.F., en el año 2000, expresa que la responsabilidad en sentido jurídico debe entenderse, desde la perspectiva de una persona que ejecuta un acto libre, como la necesidad en la que se encuentra la persona de hacerse cargo de las consecuencias de sus actos.

La responsabilidad jurídica se encuentra siempre asociada a una norma de carácter imperativo que impone obligaciones. Al hablar de responsabilidad jurídica debemos vincular varios conceptos, por una parte el ser humano como sujeto con capacidad de actuar, que ese actuar pueda afectar el mundo jurídico que lo rodea, ósea modificar, crear o suprimir situaciones de carácter jurídicas contempladas en normas imperativas, que podrían ser sinalagmáticas o no, en todo caso, siempre existirá una parte que tendrá la potestad de solicitar a la otra el cumplimiento de un precepto legal, así sea en un sentido más amplio, la sociedad como sujeto de derecho la que tenga esa posibilidad, de igual modo en aquellas acciones de tipo sociales, acciones de grupo, acciones populares o como se denominen de acuerdo a las normativas de cada país.

\subsubsection{Diferentes clases de responsabilidades en que puede Incurrir un profesional de la salud en Colombia}

Colombia siempre ha estado blindada de sistemas normativos que permitan la reclamación de daños o perjuicios en contra de sus responsables, no en vano podemos citar que nuestro código civil data de 1.887 y es reflejo del Code Civil promulgado en Francia por Napoleón, de fecha 21 de marzo de 1804'; el Libro IV del código civil, correspondiente a las obligaciones en

1 El Código Civil comprende las disposiciones legales sustantivas que determinan espe- 
Análisis de la carga de la prueba de la pérdida de oportunidad en la responsabilidad civil médica en Colombia

general y de los contratos (artículos 1494 al 2545), trata en sus primeros artículos el tema de la fuentes de las obligaciones, su nacimiento y la obligatoriedad de reparar el daño causado como consecuencia de acciones u omisiones de algún sujeto que en ultimas será catalogado como responsable de los daños ocasionados. (Leer articulo 1902 C.Ci.).

Siguiendo al Tratadista Sergio Yepes Restrepo, en su texto "La responsabilidad Médica civil" (Restrepo, 2008) expone una clasificación que denomina según el ámbito o la causa, que viene a diferenciarse en cuanto a la codificación, disposiciones legales, por lo tanto, régimen aplicable y la sanción por incumplimiento de las normas, catalogando las responsabilidades producto del actuar del profesional de la salud en:

a. Responsabilidad Ético-disciplinaria:soportada en aquellos códigos éticos y deontológicos, que rigen a los profesionales de la salud (Ley 23 de 1981, en materia médica, y la ley 35 de 1989, en odontología).

b. Responsabilidad Disciplinaria: cuando el profesional de la salud ostenta la calidad de funcionario público, ciertas conductas pueden dar pie a un proceso de carácter disciplinario, con un juzgador natural, la Procuraduría General de la Nación.

c. Responsabilidad Laboral: por reglamentos internos de cooperativas, empresas, sociedades científicas, entidades promotoras de salud e instituciones prestadoras de servicios de salud de carácter privados, regulan deberes de los profesionales de la salud, sancionándolos en caso de incumplimiento.

d. Responsabilidad Administrativa: normas de carácter administrativas de obligatorio cumplimiento por las entidades promotoras de salud e instituciones prestadoras de servicios.

e. Responsabilidad Penal: conductas tipificadas como delitos en el código penal y cuya realización amerita por parte del Estado una sanción penal.

cialmente los derechos de los particulares, por razón del estado de las personas, de sus bienes, obligaciones, contratos y acciones civiles. Tomado de Galindo, Laura. (2011). Evolución del Código Civil Colombiano. Trabajo presentado en la Universidad de Los Andes, Facultad de Derecho. Bogotá D.C. 
f. Responsabilidad contenciosa Administrativa: cuando se encuentra involucrado como prestador del servicio de salud un ente de carácter público.

g. Responsabilidad Civil: que se traduce en la reparación de los daños causados al paciente o sus familiares a través de una indemnización de los perjuicios ocasionados.

Cada país ha adoptado de forma diferente sus sistemas de responsabilidades en materias médicas; tratándose de responsabilidad contenciosa administrativa y civil médica, tanto en Francia como en Colombia existe una dualidad de jurisdicciones, en Italia la responsabilidad civil se encarga de los casos de responsabilidad médica realizada en el ámbito público o en el privado (Fernández, 2008).

Así mismo, una conducta puede dar lugar a diversas responsabilidades, sin que necesariamente estas se excluyan entre sí, valorando que en Colombia las indemnizaciones de perjuicios derivados de daños, no son fuente de enriquecimiento, sino un factor que permita colocar al paciente, víctima o familiares, en la situación exactamente anterior al daño, o al menos, lo más próximo a esta, por lo que se habla de reparación de perjuicios, en palabras de la Corte Constitucional "El resarcimiento del perjuicio, debe guardar correspondencia directa con la magnitud del daño causado, mas no puede superar ese límite", a diferencia de sistemas donde se utilizan las indemnizaciones a modo de reproches sociales o ejemplarizantes, como en los sistemas de common law, principalmente en países como Estados Unidos, bajo el denominado daño punitivo o punitive damage (Matamorros, 2003).

\subsubsection{De la responsabilidad civil profesional}

La responsabilidad tan solo viene definida en sus distintas clases o especies: civil, penal, administrativa, entre otras; pero el hecho característico es cuando un profesional liberal con su conducta incurra en ella, dándole una característica diferente, por lo que se estima que es una responsabilidad especial en atención a dos situaciones particulares, por un lado, el carácter profesional del prestador del servicio, en concreto del médico o profesional de la salud en general; y por otro, la mayor intensidad de su responsabilidad (Costales, 1995). 
Cada una de las actividades denominadas como liberales, entiéndase arquitectos, abogados, médicos, etc., poseen características diferenciadoras, que una vez enmarcadas dentro del tema de la responsabilidad, comportan unas cualidades especiales que las hace diferentes entre ellas mismas, y de esa manera actuará la institución de la responsabilidad sobre ellas; sin embargo, tienen unos aspectos que se pueden denominar como comunes o generales, tema que se encuentra desarrollado de una forma clara en el texto manual del seguro de responsabilidad civil de la fundación Mapfre (Mapfre, 2004), agrupándolas de la siguiente manera:

a. Previa contratación a través de un contrato de prestación de servicios: por lo general la relación que vincula al cliente con el profesional, se maneja a través de la figura del contrato de prestación de servicios, que impone obligaciones intituo personae. El cliente contrata al profesional en razón de sus cualidades personales, su saber profesional, su conocimiento sobre la materia y aspira que sea únicamente este, quien realice la labor para la cual fue contratado. La relación se desarrollada mediante contrato de prestación de servicios. La anterior interpretación sobre la existencia de contrato previo, no excluye la existencia de supuestos donde la responsabilidad civil profesional sea extracontractual.

b. Los elementos para estructurar la responsabilidad civil profesional son los generales para cualquier tipo de responsabilidad, una acción u omisión antijurídica, la existencia de un daño, la relación de causalidad o nexo de causalidad entre ambos y la existencia de culpa o negligencia.

c. La regla general es que nos encontramos ante obligaciones de medios y no de resultados, lo que implica que el profesional pone todo su conocimiento, experiencia y cualidades para resolver de la manera más adecuada la labor a él encomendada, sin que la no obtención del resultado esperado implique la responsabilidad del profesional.

d. La responsabilidad civil profesional, trae un aspecto muy propio y característico de ella, que es el reconocer la transgresión de la denominada "lex artis" o "lex artis ad hoc", conjunto de reglas profesionales generalmente aceptadas para un caso concreto.

Los aspectos que hemos enunciado de forma general, no son limitaciones para que en cada profesión se den otras características. 


\subsubsection{La responsabilidad civil médica en Colombia}

Una obligación en sentido jurídico, no es otra cosa que un vínculo en virtud del cual una persona llamada deudor está constreñida (obligada) a dar a otra, llamada acreedor, una cosa, o a realizar un hecho positivo o negativo, no es otra cosa que cumplir algo, a lo cual nos hemos comprometido ${ }^{2}$. Este algo o aspecto que debemos cumplir, puede estar enmarcado en una norma, en un convenio, en un contrato, en un cuasicontrato o ha nacido de un delito; entre el galeno y su paciente, nace un vínculo obligacional, donde existen prestaciones reciprocas, que se desarrollan a través de hechos jurídicos lícitos.

Ahora bien, la responsabilidad civil del galeno viene dada cuando esos hechos jurídicos han generado infracciones de carácter ilícitas. La responsabilidad civil médica está dada o tendrá su fundamento en los hechos de carácter ilícitos, que se han generado del vínculo obligacional entre el galeno y el paciente, en sentido amplio, entre el sector salud privado y un paciente.

\subsubsection{De la responsabilidad civil contractual y extracontractual tratándose de la profesión de la medicina}

Como manifiesta Miriam Cueto Pérez (1997), doctora en Derecho, desde que el hombre cambia su modo de vida y asume el vivir en sociedad, de sus acciones u omisiones se derivan daños a los bienes, derechos de los demás y podemos agregar daños entre ellos mismos, en esa medida mientras esa convivencia se intensifica, se van creando nuevas relaciones y este tipo de comportamientos resultan inevitables. Es allí donde, a través de los institutos jurídicos de las responsabilidades, se aportan soluciones, así cada comportamiento dañoso causado a otro integrante del conglomerado social irá unida una sanción jurídica, que obliga al sujeto activo de la conducta a reparar los daños causados a los perjudicados.

Tradicionalmente las conductas que comportan daños sociales vienen enmarcadas en dos regímenes, los cuales se identifican de acuerdo al origen

2 Para profundizar sobre el tema de las Obligaciones consultar Pérez Vives, Álvaro. Teoría General de las Obligaciones. Vol. I Parte Primera De las Fuentes de las Obligaciones. Ediciones Doctrina y Ley. Bogotá - Colombia. Leer artículo 1495 del Código Civil, sobre fuentes de las Obligaciones. 
Análisis de la carga de la prueba de la pérdida de oportunidad en la responsabilidad civil médica en Colombia

o su fuente, por un lado, el daño puede derivarse del incumplimiento de un pacto previamente establecido, estaremos entonces ante una responsabilidad de tipo contractual; por otro lado, si el daño proviene de una relación de carácter genérica la cual se encuentra fuera del ámbito de cualquier relación jurídica previa entre las partes, nos encontramos ante una responsabilidad de tipo extracontractual.

El sistema normativo colombiano acoge la teoría dualista de separación, existente entre la responsabilidad civil contractual y extracontractual, definiendo la responsabilidad civil contractual como la resultante de la inejecución o ejecución imperfecta o tardía de una obligación estipulada en un contrato válido, siendo un derecho de crédito de orden privado y orbita dentro de un campo exclusivo y limitado; es decir, cualquier tipo de perjuicio ocasionado solo debe ser originado por el incumplimiento, y de acuerdo a lo que hayan pactado las partes. Mientras que la responsabilidad civil extracontractual es aquella que no tiene origen en un incumplimiento obligacional, sino en un hecho jurídico (delito o ilícito de carácter civil), generando que exista una gran diferencia en sus efectos.

La primera obedece a la autonomía de la voluntad privada, por un acuerdo de voluntades que es ley solo para las partes, y la otra se produce como consecuencia de la voluntad del Estado plasmada en la ley. Ambas responsabilidades se orientan hacia un mismo objetivo que es la reparación de un daño causado, el elemento subjetivo se concentra mucho más en la responsabilidad civil contractual como criterio determinante, así ambas sean de tradición culpabilista, como expresamente lo señalan los artículos 63, 1604, 2341 y 2356 del Código Civil colombiano.

La Corte Suprema de Justicia de Colombia ${ }^{3}$ señala que el pago de una indemnización por daños causados en la responsabilidad civil contractual pueden definirlo las partes, mientras que en la responsabilidad civil extracontractual pueden verse afectados bienes jurídicos, donde solo el Estado, a través de su poder impositivo y coactivo, puede intervenir incluso de manera oficiosa, como es el caso de los daños causados por el ejercicio de actividades peligrosas, donde el grave riesgo o peligro que estas

3 Esta información la podemos encontrar en la sentencia de la Corte Suprema de justicia, sala de casación civil, 24 de agosto de 2009. Magistrado Ponente Willian Name Vargas. Bogotá. 
actividades comportan para los demás, elimina toda presunción de culpa, elevándola al nivel de responsabilidad objetiva.

La concepción dualista de la responsabilidad civil que tiene el ordenamiento jurídico colombiano invita a no confundir su tratamiento por estar reguladas en forma autónoma e independiente y en capítulos distintos del código civil, ya que tienen causas diversas, y lo consignado allí en materia de reparación está lejos de coincidir. Aunque las dos compartan la existencia de un daño y este deberá ser resarcido o reparado, el régimen legal al cual se encuentran vinculadas hace que la forma de probar los daños que se tienen que resarcir o reparar cambie sustancialmente; la diferenciación entre ambas responsabilidades tiene su importancia más en el aspecto procesal que en la contemplación teórica de ambos (Fundación Mapfre, 2004).

Con el tiempo y con el advenimiento de nuevas doctrinas, los tribunales abandonaron su posición y admitieron que la responsabilidad de los profesionales de la medicina podía ser también de tipo contractual, según el $\mathrm{caso}^{4}$, exigiendo la culpa como requisito para establecer la responsabilidad del médico en todos los casos. En Francia desde 1936 se adoptaría la naturaleza contractual de la responsabilidad médica como regla general.

Nuestra jurisprudencia, de igual forma, fue en caminándose hacia esa doctrina, desde la sentencia del 5 de marzo de 1940 se manejó que la responsabilidad de los profesionales de la medicina podía ser de tipo contractual o extracontractual, según el caso, al igual que se desarrolló que la obligación del galeno era una de obligación de medios y no de resultados, sobre lo cual profundizaremos más adelante.

Habrá entonces circunstancias que no se encuentran relacionadas con el acto medicó como tal, o bien, otras en las cuales no medie un previo acuerdo entre paciente-médico, por ende, esos daños causados por el médico generan una responsabilidad civil de tipo extracontractual (por fuera de un contrato), sin adéntranos en el ámbito de la obligación

4 Fallo Thouret-Noroy del 18 de junio de 1935 en Francia, manifestaba que la responsabilidad médica solo tenía un fundamento delictual, sin embargo el fallo Mercier de fecha 20 de mayo de 1936, otorgo a la la responsabilidad médica un fundamento contractual. Consultar a la Doctora Fernández M, Mónica Lucía. (2008). La Responsabilidad Médica: Problemas Actuales. Grupo Editorial Ibáñez. Bogotá - Colombia. 
subyacente de seguridad que expondremos más adelante, consideramos que para determinar la existencia de responsabilidad civil extracontractual o contractual del médico, habrá que delimitar, por una parte, las obligaciones inherentes al contrato de prestación de servicios médicos, pues esta nos ayudará a determinar el acto médico contratado; y por otra parte, una delimitación temporal espacial de esa obligación.

El tratadista Javier Tamayo Jaramillo, en sus obras "Tratado de Responsabilidad Civil" y en su monografía titulada "Sobre la prueba de la culpa médica" (Jaramillo, 2010) expone varias situaciones que nos podrán servir como ejemplos, en la cual se menciona que cualquier daño producido antes o después de que el médico actué sobre el paciente, solo compromete la responsabilidad extracontractual del médico por no existir aún la obligación contractual, el togado cita un fallo de la sala civil de la Corte de Casación Francesa de fecha 10 de enero de 1990, que determinó que "el contrato celebrado entre el centro médico y el paciente se limita a la consulta y a los cuidados.", en cambio cualquier daño que sufra el paciente cuando está bajo el cuidado del médico será contractual.

La distinción entre responsabilidad civil contractual y extracontractual, se fundamenta cuando se trata de establecer responsabilidades al interior de los equipos de trabajo médicos, el cirujano a cargo de una intervención responderá contractualmente por la culpa en que puede incurrir un miembro del equipo de trabajo, que no se encuentra ligado contractualmente al paciente, pero si ambos han contratado con el paciente, ambos responden contractualmente.

\subsubsection{Obligaciones de medios y obligaciones de resultado}

Las obligaciones de medios son aquellas obligaciones del deudor, en la cual su compromiso se encuentra ligado a la utilización de medios idóneos en la realización de la tarea a él encomendada, mientras que en las obligaciones de resultado lo importante es el resultado obtenido. Cuando el deudor se compromete a realizar una actividad, estamos en presencia de las obligaciones de medios, con total independencia de las consecuencias. $\mathrm{Su}$ compromiso estriba en desplegar una actividad diligente, dirigida a satisfacer, en lo posible el interés primario del paciente, que dista de un resultado particular. Por lo que su cumplimiento o incumplimiento son independientes del resultado esperado por el acreedor. Depende única y 
exclusivamente de la actuación diligente o negligente del deudor, por lo que no se podrá endilgar responsabilidad bajo el supuesto de que no se obtuvo el resultado esperado. La obligación se traduce en colocar o dispensar los medios indispensables y necesarios.

Cuando el deudor no solo se compromete a desplegar y desarrollar una actividad básica, sino a cumplir un resultado, de modo que, si no obtiene el resultado, no se extingue la obligación a su cargo, por más diligencia que haya empleado, habida consideración que el cumplimiento en esta tipología prestacional, no se reduce a tratar o intentar, sino a conseguir resultados efectivos.

Tratándose de responsabilidad médica, diversos debates se han planteado sobre las obligaciones que adquiere el galeno y su naturaleza. Con el ya mencionado fallo Mercier del 20 de mayo de 1936 en Francia, la jurisprudencia acogió la distinción promulgada por Demogue, considerando que la obligación del médico era de medios y no de resultado (Fernández, 2008):

Entre el médico y su cliente se forma un verdadero contrato que comporta, para el médico, el compromiso, si bien no de curar al enfermo, al menos de procurarle los cuidados médicos (asistencia médica), pero no cualquier cuidado, sino cuidados concienzudos, atentos y, salvo circunstancias excepcionales, conformes a los datos adquiridos de la ciencia.

El aleas, específicamente el aleas terapéutico, nos muestra que la curación de un paciente no necesariamente se encuentra ligada únicamente a los cuidados diligentes de su médico, a su pericia profesional, la curación se encuentra ligada en gran medida a factores exógenos que escapan a su actuar, por lo que el médico deberá solo comprometerse a lo que efectivamente podrá garantizar, que es la utilización de los medios idóneos cuya naturaleza consientan en llegar a un resultado, pero en ninguna medida directamente al resultado.

En la práctica, las obligaciones de resultado son el aspecto general y las de medios son la excepción, aunque en el campo de la medicina sean la regla general por la prestación debida; ambas se traducen en obligaciones de hacer, lo que entraña un preciso y delimitado comportamiento o una actitud a cargo del deudor. Por lo que el primer campo es determina que 
Análisis de la carga de la prueba de la pérdida de oportunidad en la responsabilidad civil médica en Colombia

estamos en presencia de prestaciones de hacer, una actuación de carácter positiva, encaminada a la satisfacción del derecho crediticio radicado en cabeza del acreedor.

Nuestra jurisprudencia ha sido influenciada por el fallo Mercier de 1936, por lo que nuestra Corte Suprema consagró en el fallo de 5 de marzo de 1940, acogiendo que, por regla general, la obligación del médico no es de resultado si no de medios. Siguiendo la misma línea, en sentencia de fecha 12 de septiembre de 1985, la corte señala, que hoy no se discute que el contrato de servicios profesionales implica para el galeno el compromiso, si no exactamente de curar al enfermo, si al menos de suminístrarle los cuidados concienzudos, solícitos y conformes con los datos adquiridos por la ciencia, por lo que el médico solo se obliga a poner en actividad todos los medios que tenga a su alcance para curar al enfermo.

Por regla general, el profesional médico adquiere obligaciones de medios, por lo que su actuar deberá ser con prudencia y diligencia en el acto médico encomendado, tratándose de obligaciones de resultado, la jurisprudencia y la doctrina han reconocido ciertos casos de intervenciones o procedimientos médicos, que por sus especiales características son denominados de resultado, como la responsabilidad sin culpa de los médicos y de los establecimientos hospitalarios por defecto de los productos de salud (en Francia); la responsabilidad de los establecimientos por infecciones nosocomiales; la obligaciones de exactitud inherentes a ciertos exámenes corrientes y simples; cuando el médico de forma consiente se obliga a obtener un resultado; las cirugías estéticas embellecedoras (sentencia 2423, 1986), dejando por fuera las reparadoras que siguen la regla general; la obligación del médico obstetra consistente de traer un bebé al mundo luego de haberse desarrollado un embarazo regular (sentencia, 12123, 2000); la utilización de cosas peligrosas durante la realización de un acto médico ${ }^{5}$; la obligación de seguridad derivada del contrato de hospitalización ${ }^{6}$; la obligación de custodia y vigilancia a cargo de los establecimientos mentales (sentencia 3532, 1993); la práctica de exámenes radiológicos (sentencia 12655, 1999); la obtención de exámenes de laboratorios (sentencia 12548,

5 Véase con precisión en la sentencia de la Corte Suprema De Justicia, sala de casación civil, 14 de octubre de 1959. m.p. hernando morales.

6 Véase con mayor precisión en la sentencia de la Corte Suprema De Justicia, sala de casación civil, 12 de septiembre de 1985. m.p. horacio montoya gil. 
2000); la obligación de realizar la intervención médica; la ejecución de exámenes de diagnósticos; la obligación de utilizar equipos o instrumentales especializados que faciliten la labor del cirujano; algunas cirugías odontológicas como fijaciones de prótesis dentales o blanqueamiento estético; ciertos procedimientos como vasectomía o ligaduras de trompas; y la realización de procedimientos donde se pueden garantizar resultados, tales como una operación de amígdalas, la apendectomía, los procedimientos ambulatorios entre otros (Fernández, 2008).

La distinción entre obligaciones de medios y de resultado, tendrá su importancia práctica al momento de la materialización de los daños y más aún en la forma en que la persona que se encuentra afectada desea probarlos, en la forma en que el demandante deberá desplegar la carga probatoria para lograr que su pretensión prospere.

Siendo la obligación del galeno por regla general una obligación de medios, el demandante tendrá que probar la culpa del médico, que este no utilizó los medios concienzudos, solícitos y que no actuó conforme con los datos adquiridos por la ciencia, que su pericia médica así lo indicaba.

\subsubsection{De los actos médicos y sus características especiales}

La actividad medica comporta una series de facetas que la hacen especial, diferente a cualquier otra, sobre todo si consideramos que se desarrolla en el marco de un área sensible, que debe ser protegida desde cualquier punto de vista, como es el cuerpo humano, donde se vinculan una serie de elementos, el modo en que se interactúa influye para que los ojos de la sociedad la vigilen; no podemos desconocer que dentro del campo de acción o de la relación médico-paciente siempre van a estar inmersos aspectos tales como la dignidad humana, el respeto al ser humano, la inviolabilidad de la libre disposición y muchos otros factores determinantes para que la práctica de la medicina, sea considerada una de las profesiones más importantes de nuestra sociedad, todo esto desarrollado a través de la relación que el galeno pueda entablar con su paciente en el acto médico.

El acto médico se concreta en la relación médico-paciente por lo que en realidad viene a ser una forma especial de relación entre personas, una de ellas con unos conocimientos científicos, adquiridos a través de años de estudios de las técnicas y protocolos médicos para tratar enfermedades, y 
otra que, por lo general, presenta una dolencia que imposibilite el normal desarrollo de su vida; el enfermo, quien acude motivado por esa alteración en su salud al médico, quien debe estar en capacidad de orientar y tratar para sanar, después de hacer un análisis de la situación, determinando el tipo de enfermedad que el primero presenta.

A medida que la medicina avanza resulta más difícil hablar de acto médico, en sentido estricto y de forma singular, la modernidad, con los avances científicos conlleva a que hablemos del acto médico como un acto complejo, podemos encontrar que existen actualmente actos de prevención, de diagnóstico, de prescripciones médicas, de tratamientos médicos, de rehabilitación, entre otros, desarrollados, en algunos casos, por un grupo de especialistas, lo que influye de forma directa sobre la responsabilidad médica.

El acto médico es la forma mediante la cual el médico desarrolla su actividad, utilizando toda su experticia y conocimiento científico-medico, para procurar aliviar o curar la patología o enfermedad que presenta el paciente. A través del acto médico se promueve la salud, se previene la enfermedad, y rehabilita al paciente.

Como plantea Mónica Liliana Osorio Arango, Doctora, en su trabajo de tesis denominado "Breve aproximación a algunos aspectos de la responsabilidad penal medica", el acto médico posee cuatro características: solo puede ser realizado por una profesional de la medicina, lo que plantea una profesionalización; su ejecución debe estar de acuerdo a la "lex artis ad hod", lo que plantea una ejecución típica; debe tener un objetivo de curación o rehabilitación del enfermo, un fin altruista; y debe estar sujeto a las normas imperantes, debe ser licitó.

Los actos médicos pueden ser de carácter directo, indirectos (Arango, 2002) y documentales; los de carácter directo son aquellos mediante los cuales el galeno realiza intervenciones médicas con el objetivo de obtener la curación o alivio del enfermo, sin que el médico pueda comprometerse a obtener el resultado. Como bien lo hemos indicado, comprometiéndose a utilizar toda su pericia y conocimiento, en el procedimiento avalado por la ciencia médica. Pueden ser preventivos, diagnósticos, terapéuticos o de rehabilitación. 
De los actos médicos la doctrina pregona, que se pueden desprender dos tipos de consecuencias de carácter jurídicas, las que tienen su fuente en el acto jurídico ("responsabilidad" por el acto) y las que tienen su fuente en los hechos jurídicos ("perjuicios" indemnizables por el hecho antijurídico capaz de generar implicaciones en el).

Estos tipos de consecuencias, solo son posibles en la medida que existan normas jurídicas que impongan obligaciones o de contenido obligacional, como las que encontramos en códigos, ya sea civiles o penales, en las cuales aparecen vinculados aquellos derechos que denominamos de carácter subjetivo de las partes que intervienen en el acto médico, como son el profesional médico y su paciente.

Las actuaciones del médico, por lo regular van precedidas de un acto jurídico (contrato consensual); si el médico lo cumple, genera derechos a su favor y si lo incumple, genera sanción. Es preciso, como lo hemos manifestado en párrafos anteriores, que por regla general y en la mayoría de los casos, una obligación de medios y solo en algunos eventos, una obligación de resultado, el acto jurídico se cumple a cabalidad siempre que el médico haga lo correcto o lo incumple, si no actúa en concordancia con los preceptos médicos científicos aceptados.

Si el resultado es bueno, surge en favor del profesional de la salud un crédito, un derecho a cobrar honorarios. Si el resultado afecta derechos del enfermo, surge en su contra la responsabilidad, la cual se juzga, precisamente, con base en la Lex Artis.

El doctor Carlos Ignacio Jaramillo, en su obra denominada "Responsabilidad Civil Médica" (2002), hace referencia a las diferentes particularidades que componen la actividad médica, facetas que le otorgan un carácter particular al acto médico como tal, las cuales mencionan que son la dimensión técnico-funcional; la dimensión ética y la dimensión jurídica.

Esto para significar que el acto médico comporta una serie de aristas, las cuales tendrán que ser analizadas en su conjunto, cuando intentamos desentrañar el gran espectro de la responsabilidad de los galenos, sea que nos encontremos en el campo civil, penal u otro, que su importancia radica en donde este se materializa, de la misma manera en que el ingeniero puede desarrollar su labor en una construcción y crear grandes edificaciones, de 
Análisis de la carga de la prueba de la pérdida de oportunidad en la responsabilidad civil médica en Colombia

esa manera el médico desarrolla su labor en el cuerpo humano, lo sana, rehabilita y recupera.

\subsubsection{Sobre la "lex artis" y "lex artis ad hoc"}

Estos conceptos fueron desarrollados por la jurisprudencia, convirtiéndose en conceptos inseparables del tema de la responsabilidad médica. Cuando hablamos de lex artis, bien podemos traer el concepto que manejó el Tribunal Supremo de España, en su sentencia del 11 de marzo de 1991, que fue el criterio adoptado por nuestra Corte, y señalaba que esta consiste en:

... Aquél criterio valorativo de la corrección del concreto acto médico ejecutado por el profesional de la medicina-ciencia o arte médico que tiene en cuenta las específicas características de su autor, de la profesión, la complejidad del acto y la trascendencia vital para el paciente y, en su caso, la influencia de factores endógenos estado e intervención del enfermo, de sus familiares o de la misma organización sanitaria para calificar dicho acto conforme o no a la técnica normal empleada.

Nos referimos a la lex artis como criterios o reglas de caracteres generales aplicados a casos iguales o parecidos, conforme a criterios objetivos de cuidados, estamos ante casos o situaciones previamente estudiadas y conocidas, hay que valorar el estado de los conocimientos científicos y técnicos, agregando el respeto de las pautas deontológicas, éticos y derecho médicos; lo importante es atender a la existencia o no del cumplimiento, de reglas técnicas incuestionables, que pueden estar o no estandarizadas y protocolizadas, pero son generales y adaptables al caso concreto, que de formas directa su incumplimiento fue la causa del daño.

En las últimas jurisprudencias el concepto de lex artis (ley de las artes), se utiliza como criterio delimitador de responsabilidad. Así, la sentencia del tribunal supremo de 22 de diciembre de 2001 une el concepto de infracción de la misma con el relativo a la antijuridicidad del daño, y considera que, si la intervención de que se trate está indicada, y se ha realizado conforme al estado de la ciencia o del saber en el momento de la misma, el resultado dañoso que pueda producirse no es antijurídico; es decir, no es contrario a la norma y, por tanto, el paciente tendría obligación 
de soportarlo. "No serán indemnizables los daños que se deriven de hechos o circunstancias que no hubiesen podido prever o evitar según el estado de los conocimientos de la ciencia o de la técnica existentes en el momento de producción de aquéllos...".

La lex artis o lex artis ad hod, como norma de conducta, se analiza acompañada del parámetro abstracto y subjetivo de la conducta del profesional médico, acudiendo a un parámetro que se ha denominado el comportamiento del buen profesional.

\section{Teoría de la pérdida de oportunidad en el ámbito de la responsabilidad médica}

El galeno o profesional de la salud tiene una responsabilidad con la sociedad y obligaciones jurídicas, las cuales se encuentran divididas en una serie de obligaciones que de frente a la actividad médica y al contacto con los pacientes hacen que esta obligación sea de carácter complejo.

Aunque el médico no se encuentre formalmente obligado a obtener un resultado final en la atención, su comportamiento durante el desarrollo del acto médico sí puede influir directamente en la manera que el tratamiento sea acogido por el organismo del paciente, de modo que, puede ser acogido de forma grata o no generar los resultados esperados por circunstancias como demoras en su aplicación, un diagnóstico incorrecto o un tratamiento errado.

Nuestras altas cortes, han intentado desde el mundo jurídico darle sentido a la obligación del galeno, mezclando la responsabilidad social de esta actividad y surgiendo diversas teorías que permitan verificar la tipología de daños que genera el actuar galénico dentro de su desarrollo. Una de esas teorías es la denominada por la doctrina la pérdida de oportunidad, concebida como un perjuicio autónomo, que debe ser reparado de forma independiente al daño final que puede causar una mala praxis.

La Sección Tercera el Consejo de Estado expone que la pérdida de oportunidad como perjuicio autónomo, en su ámbito probatorio tendrá matices también autónomos. El Consejo de Estado, con fecha del 25 de octubre del 2013, Sección Tercera, sentencia 68001231500019951119501 (25869), Consejero Ponente, Enrique Gil, se expresa, con respecto a la 
pérdida de oportunidad, que este tipo de daño surge cuando la actuación de la administración reduce la expectativa que pudo haber tenido la víctima de padecer una pérdida menor, entendiendo por administración la actividad médica desplegada por una institución de carácter público.

El paciente como consecuencia de una patología que determina el decaimiento de su estado de salud, deteriorando su condición física, posee de cara al tratamiento médico adecuado e idóneo que la ciencia, el arte y los protocolos médicos han determinado para tratar su afección, porcentajes o expectativas de obtener beneficios en el restablecimiento de su salud.

Cuando existe un acto de los denominados mala praxis médica, actividad medica desplegada de manera deficiente por una institución o galeno, estas expectativas son interrumpidas de manera dramática, y se evidencia que el porcentaje de favorabilidad frente a la reacción del tratamiento disminuye de manera ostensible, el paciente pierde la oportunidad de obtener esa mejoría a sus patologías, generando así un daño físico por la pérdida de esa oportunidad de recuperación, daño de carácter autónomo con matices probatorias autónomas.

El Consejo de Estado sigue expresando que ese daño se evidencia cuando no es posible establecer un nexo causal entre la actuación de la autoridad estatal y la afectación concreta que sufre el demandante, a través de las pruebas arrimadas al proceso. Según la providencia, para cuantificar el daño, es necesario que el juez aplique un análisis estadístico a la valoración del material probatorio, ante la imposibilidad de atribuirle al causante del perjuicio toda la responsabilidad por la afectación que sufra el accionante.

En el caso analizado por el Consejo de Estado y que nos ha servido como base para nuestros argumentos iniciales, el demandante había sufrido la amputación de una de sus piernas tras un accidente de tránsito. La Sección concluyó que se trataba de un desenlace previsible, aun en el entendido de que el procedimiento médico que se le brindara no hubiera derivado en contratiempo alguno. Incluso, determinó que todos los procedimientos se dieron de acuerdo con la técnica y la necesidad requeridas por el estado del paciente. Sin embargo, también encontró que las demoras excesivas dieron lugar a la pérdida de oportunidad que tenía la víctima de prolongar su expectativa de salir mejor librada de este acontecimiento. 
Es decir, que la responsabilidad no se configura por la pérdida de una de las extremidades de la víctima, sino porque la actuación de la administración redujo su esperanza de no sufrir una pérdida de esas dimensiones, concluyó la corporación. La Sección Tercera del Consejo de Estado indicó que el daño por pérdida de oportunidad constituye el cercenamiento de una ocasión aleatoria que tenía una persona de obtener un beneficio o de evitar un deterioro. En el caso de la posibilidad benéfica, si bien, no es posible vislumbrarla con toda certeza y sin el margen de duda que se hubiese materializado en la situación favorable esperada, no se puede desconocer que existía una probabilidad considerable de haberse configurado la misma.

De este modo, el Consejo de Estado ha delimitado y definido de manera clara esta teoría, en la Sección Tercera, sentencia 630012331000200300261 (38267), de fecha mayo 31 del 2016, Consejero Ponente Danilo Rojas Betancourth. Precisa que esta pérdida de oportunidad es un daño autónomo, demostrando que no siempre comporta la vulneración de un derecho subjetivo, toda vez que la esperanza de obtener un beneficio o de evitar una pérdida mayor forma un bien jurídicamente protegido, cuya afección debe limitarse a la oportunidad en sí misma, con exclusión del resultado final incierto, esto es, al beneficio que se esperaba o a la pérdida que se pretendía eludir, los cuales constituyen otros tipos de daño. Sin embargo, la pérdida de oportunidad puede llegarse a confundir con otras figuras que en su aplicación podrían presentar similitudes, tales como el daño ocasionado por dificultad al obtener beneficio o evitar una pérdida, y pérdida de una probabilidad.

En concordancia con la providencia antes citada, se ha distinguido entre el daño consistente en la imposibilidad definitiva de obtener un beneficio o de evitar un perjuicio, caso en el cual el objeto de la indemnización es el beneficio dejado de obtener o el perjuicio que no fue evitado y la pérdida de una probabilidad que, aunque existente, no garantiza el resultado esperado, pese a que estaba dispuesto a su obtención en un porcentaje que constituirá el objeto de la indemnización. De igual forma, precisó que para que resulte procedente indemnizar la pérdida de una oportunidad, se requiere que la ocasión sea cierta y exista, pues, si se trata de una posibilidad muy genérica se estará en presencia de un daño hipotético o eventual que no resulta indemnizable. 
Para que pueda acreditarse la existencia del daño, el demandante deberá probar "el no haber podido obtener la ventaja que esperaba es consecuencia de no haber gozado de la oportunidad que normalmente le habría permitido obtenerla".

La teoría de la pérdida de oportunidad, también conocida como pérdida de posibilidad o en Francia como Chance, viene a constituirse en una nueva teoría de la causalidad, que opera por incertidumbre causal, aplicada cada vez más por nuestros operadores jurídicos en los casos de responsabilidad médica.

\subsection{Etimología de la pérdida de oportunidad}

La pérdida de oportunidad "expresión que se emplea usualmente en el ámbito de la responsabilidad civil para hacer referencia al daño que sufre quien ve comprometida una posibilidad real de obtener un beneficio o evitar un menoscabo. La jurisprudencia y doctrina lo han tomado del sistema jurídico francés", en el cual se utiliza la palabra Chance, ligada a la palabra azar, en un sentido de suerte o fortuna, oportunidad, posibilidad o probabilidad. En ese sentido, la responsabilidad civil hará alusión a la pérdida de una ocasión favorable o de obtener algún provecho o utilidad. Lo contrario de una oportunidad sería un riesgo, en que podría hablarse más bien de mala suerte y no de buena suerte.

La doctrina de la perdida de oportunidad trata de la probabilidad, pero cuando esta es significativa, cuando las posibilidades de que la víctima hubiera por cierto el hecho causal, la victima puede tener derecho a un resarcimiento (parcial) en concepto de Chance irreversiblemente sacrificada. Pero se debe tener en cuenta que en dicha oportunidad debió existir una posibilidad real, seria y no una situación de eventual utilidad, ya que en este caso caeríamos en un abuso de la figura.

La pérdida de oportunidad es un medio subsidiario, ya que solo se usa cuando es imposible demostrar que esa conducta generó ese daño, cuando es imposible establecer el nexo causal entre el comportamiento del galeno y el daño sufrido por el paciente. Es utilizada en los casos de incertidumbre causal, este planteamiento se deriva de que hay "casos en los que no puede establecerse si una determinada conducta ha provocado un daño, pero se da por bueno que, con el comportamiento debido, habría 
existido posibilidad de que el resultado lesivo no se hubiera producido". Se delimita la indemnización al valor de la ventaja dejada de obtener, económica o personal, la cual no puede superar o ser igual a la indemnización que hubiera recibido por la pérdida de la ventaja, es decir, en el caso en que no se hubiera dado la incertidumbre causal.

\subsection{Requisitos para considerar la pérdida de oportunidad como daño indemnizable}

La pérdida de oportunidad como daño autónomo indemnizable, debe agotar unos requisitos para su configuración, de la siguiente manera:

a. Certeza respecto de la existencia de una oportunidad que se pierde. La certeza sobre cómo ese tratamiento específico genera de cara a la patología un beneficio, que de acuerdo a los protocolos médicos y de la ciencia se encuentran ya plenamente identificados y demostrados.

b. Imposibilidad definitiva de obtener el provecho o de evitar el detrimento. Dada la actuación del galeno o la institución, la omisión, mala praxis, impiden de manera total que se materialicen los beneficios que efectivamente la ciencia médica ha demostrado que aplicando de forma pertinente los protocolos médicos, el provecho a obtener es la mejoría en la patología o el no resultado dañino para el paciente.

c. La víctima debe encontrarse en una situación potencialmente apta para pretender la consecución del resultado esperado, es decir, debe analizarse si el afectado realmente se encontraba para el momento del hecho dañino, en una situación fáctica y jurídicamente idónea para alcanzar el provecho por el cual propugnaba.

Estos requisitos deben ser concurrentes para que el juzgador judicial, pueda reconocer el daño autónomo de la pérdida de oportunidad. 
Análisis de la carga de la prueba de la pérdida de oportunidad en la responsabilidad civil médica en Colombia

\section{De la carga de la prueba}

La carga de la prueba conocida también como el "El onus probandi" en su expresión latina, es el principio jurídico que señala quién está obligado a probar un determinado hecho ante el juez de conocimiento, es decir, quien posee la carga o deber procesal de llevar los medios de pruebas al proceso, para que sus pretensiones salgan adelante.

Su fundamento radica en un viejo aforismo del derecho que expresa: "lo normal se entiende que está probado, lo anormal se prueba". Por tanto, quien invoca el hecho debe demostrar las normas de derecho que sirven de respaldo a sus apreciaciones. Lo que indica este aforismo de derecho, es que el trabajo de probar un enunciado debe recaer en aquel que rompe el estado de normalidad y, por lo tanto, posee un mayor desgaste de cara al proceso.

En concordancia con lo expresado por la Doctora Magda Isabel Quintero Pérez, abogada, especialista en Derecho Procesal Civil, docente de la Universidad Libre, directora Ejecutiva del Instituto Colombiano de Derecho Procesal, quien en su artículo denominado "La distribución de la carga de la prueba: ¿deber o facultad del juez?" afirma:

Hablar de la carga de la prueba nos lleva a preguntarnos: ¿a quién le corresponde probar un supuesto de hecho?, ¿Quién resulta afectado en el proceso por no aparecer probado determinado hecho? Y, en este sentido, determinar qué debe probar cada parte en el proceso para lograr el éxito de sus intereses. Esta conducta impuesta a las partes para que acrediten la verdad de los hechos formulados en el proceso constituye una exigencia derivada del interés de cada litigante, cuyo incumplimiento deriva en la pérdida del litigio. En otras palabras, es un llamado a actuar en su propio beneficio, que corresponde con el principio onus probandi.

Sobre el particular, el Consejo de Estado ha adoptado la falla del servicio como criterio de atribución de la responsabilidad médica estatal, aunque no es menos cierto que el Consejo de Estado ha ido variando su posición respecto de la manera de probarla o de la carga probatoria, pasando desde el criterio de falta probada, aplicación de la carga dinámica 
de la prueba, falla presunta y nuevamente falla probada, pero con criterios o mecanismos de facilitación probatoria, por lo que resaltaremos el desarrollo jurisprudencial de la siguiente forma:

- La postura tradicional ha sido la aplicación de la falla probada del servicio médico.

- En sentencia del 24 de octubre de 1990, proceso No. 5902 consejero ponente Dr. Gustavo de Geriff, se inició el viraje hacia la consagración de la falla presunta del servicio médico estatal.

- Con la sentencia del 29 de noviembre del 1991, se volvió a la falla probada del servicio, utilizando como criterio diferenciador las obligaciones de medio y de resultado.

- En sentencia de 30 de julio del 1992, Ponente Dr. Daniel Suárez Hernández, se adopta definitivamente el concepto de la falla presunta.

- En sentencia de fecha 10 de febrero del 2000, utilizando como criterio diferenciador el de actividades técnicas y científicas, se adopta el concepto de carga dinámica de la prueba.

- En sentencia del 15 de agosto del 2002, expediente 11.605 el Consejo de estado vuelve a aplicar la falla presunta dentro del concepto de la carga dinámica de la prueba.

- En sentencia 1 de julio del 2004, expediente 14.696, indica que en principio la demostración de la falla del servicio corresponde al demandante, pero que excepcionalmente es procedente la inversión del deber probatorio cuando resulte difícil su prueba.

- En sentencia de 31 de agosto de 2006, se vuelve adoptar el esquema de falla probada.

- En sentencia de 11 de noviembre del 2009 se avala la existencia de instrumentos de aligeramiento probatorio, flexibilizando la prueba del nexo causal y de la falla del servicio.

- En sentencia de 28 de abril de 2010, el Consejo de Estado acoge la teoría española del daño desproporcionado, para dar probada la falla del servicio. 
Análisis de la carga de la prueba de la pérdida de oportunidad en la responsabilidad civil médica en Colombia

- Lo que evidencia que esta no ha sido una temática pacífica en esta corte, como tampoco lo ha sido en la Corte Suprema de Justicia.

\subsection{La carga de la prueba en la Corte Suprema de Justicia}

Toda decisión judicial debe fundarse en las pruebas, regular y oportunamente allegadas al proceso, sujetas a los criterios de su valoración racional e integral, de acuerdo al sistema probatorio, que para nosotros son las reglas de la sana crítica, sin perjuicio de las solemnidades prescritas en la ley sustancial para la existencia o validez de ciertos actos, con lo que corresponde al demandante y no al juez, la carga probatoria (actori incumbit probatio), al demandado corresponde demostrar in contrario (reus in excipiendo fit acto). Esto debido a que, al tenor del artículo $167 \mathrm{del}$ Código General del proceso, "incumbe a las partes probar el supuesto de hecho de las normas que consagran el efecto jurídico que ellas persiguen".

Vamos a encontrar diversos pronunciamientos al respecto, desde fallo de fecha 5 de marzo de 1940 de la Corte Suprema de Justicia, Sala Civil, que establece que la obligación del médico es de medio y no de resultado; sentencia del 12 de septiembre de 1985, la cual afirma que la obligación del médico consiste en poner en actividad todos los medios que tenga a su alcance para la curación del enfermo. Posteriormente, en sentencia del 26 de noviembre de 1986, se ratificó la doctrina, invocando la sentencia del 5 de marzo de 1940; la sentencia del 30 de enero de 2001, la línea jurisprudencial con los criterios de la Jurisdicción Civil, que evidencia la tendencia sobre la carga de la prueba en procesos de responsabilidad médica desde 1940 hasta el año 2017.

\subsection{Condiciones preexistentes y problemas de prueba en la responsabilidad civil médica}

La dificultad de la prueba del nexo causal en los procesos de responsabilidad civil médica, motivada por la multiplicidad de causas a que puede obedecer el daño sufrido por el paciente, que impide en estos casos la prueba directa de la relación de causalidad, no es posible, dado que la probabilidad de que el daño obedezca a las condiciones preexistentes del paciente impide alcanzar el umbral de convicción establecido por los diferentes ordenamientos jurídicos, lo que se ha denominado como 
incertidumbre causal. Frente al problema de la incerteza causal, se han establecido tres aproximaciones diferentes:

a. Tradicionalmente han adoptado un criterio de todo o nada, conforme al cual, o bien, no existe relación de causalidad y, por tanto, no cabe imponer responsabilidad o si concurre, la responsabilidad iguala los totales perjuicios sufridos por la víctima.

b. En ocasiones facilitan la carga de la prueba reteniendo, mayormente, las características de una aproximación de todo o nada.

c. Recientemente, acuden a la doctrina de la pérdida de oportunidad.

\subsection{Reparación de la pérdida de oportunidad}

La doctrina de la pérdida de oportunidad es un instrumento de facilitación probatoria de creación jurisprudencial, que permite estudiar la causalidad en conexión con el proceso de identificación y determinación del valor del interés destruido.

La doctrina de la pérdida de oportunidad se entiende como una teoría de causalidad probabilística, conforme a la cual, en los casos de incerteza causal mencionados, es posible afirmar que la actuación médica privó al paciente de determinadas expectativas de curación o de supervivencia, consideradas a la luz de la ciencia médica, que deben ser indemnizadas. En tal caso, es posible condenar al facultativo por el daño sufrido por el paciente, pero se reduce el montante de la indemnización en razón de la probabilidad de que el daño se hubiera producido igualmente de haber actuado aquel diligentemente.

Así, imaginemos un caso en el cual el facultativo no diagnostica que el paciente sufre un cáncer, sino cuando ya ha devenido inoperable y que, aún detectado a tiempo, el paciente sólo hubiera tenido un 30\% de probabilidades estadísticas de sobrevivir. Según la postura tradicional del Common Law, conforme a la cual el demandante debe demostrar que con un diagnóstico a tiempo la supervivencia del paciente era más probable que su muerte, con bastante seguridad no se daría compensación alguna, pues dada la reducida expectativa de supervivencia aún con un diagnóstico temprano no se satisface el umbral de certeza del 51\%. En estos casos, además, la preponderancia de la prueba apunta en sentido contrario, dado que existe una elevada probabilidad (70\%) de que la muerte del paciente se 
Análisis de la carga de la prueba de la pérdida de oportunidad en la responsabilidad civil médica en Colombia

deba al cáncer que padecía. Sin embargo, una aproximación más racional permitiría al demandante una compensación por la pérdida de oportunidad.

Si bien, en la mayoría de casos no será posible demostrar que la negligencia médica fue la causa de la muerte o del empeoramiento de la salud del paciente, si será posible acreditar que dicha negligencia le privó de una oportunidad de curarse igual al 30\%. Con ello se facilita la carga probatoria del demandante sobre la base de una causalidad aleatoria que permite presumir que el galeno, con su acción u omisión, causó un daño abstracto (la oportunidad perdida, Lost Chance) del que debe responder.

De este modo, no se considera la conexión directa entre la negligencia médica y la producción del daño, sino por un razonamiento a contrario, entre el hipotético comportamiento diligente que hubiera impedido la pérdida de oportunidad y la no producción del daño. Se dice así que esta conexión hipotética entre el comportamiento adecuado, no negligente y la no producción del daño conduce a una causalidad aleatoria entre la acción u omisión médica y el daño: un hecho cierto ha hecho perder a la víctima de un daño cierto una oportunidad hipotética de su no producción (ya que, en toda hipótesis, la certidumbre que puede afectar a la oportunidad en el plano estadístico muda en incertidumbre en el plano individual).

El daño viene así constituido por la oportunidad de curación o supervivencia pérdida a consecuencia de la actividad médico-sanitaria establecida en función de la experiencia común (daño intermedio) y no por los totales perjuicios sufridos por el paciente (daño final), con los cuales resulta en todo punto imposible establecer un nexo de causalidad debido a los umbrales de certeza determinados en cada caso.

Con todo, la evolución jurisprudencial y doctrinal comparada del principio de la pérdida de oportunidad ha transformado este instrumento procesal, que nació para aligerar la prueba de la causalidad, en una teoría sobre la calificación o determinación del perjuicio que permite tener por acreditado un daño puramente hipotético. Es frecuente, por tanto, el estudio de este principio en sede de daño y no en sede de relación de causalidad. No obstante, parece evidente que, si la noción de pérdida de oportunidad se vincula con el perjuicio, entonces se vuelve inseparable de la condición del nexo de causalidad, pues la relación de causalidad entre el acto u omisión médico-sanitaria y el perjuicio hipotético en que consiste 
la oportunidad perdida será, asimismo, una causalidad hipotética, ya que participa de su misma aleatoriedad o virtualidad.

\subsection{Límites en la aplicación de la doctrina de la pérdida deoportunidad}

Más allá de las críticas a la doctrina de la pérdida de oportunidad y particularmente en el ámbito de la responsabilidad civil médico-sanitaria, se han establecidos unos límites que contengan su ámbito de aplicación y eviten la sustitución sistemática y arbitraria de las reglas tradicionales de la causalidad y su prueba. Algunos de los criterios, ya mencionados, que sustentan la doctrina, tales como la dificultad de prueba, la injusticia a que conduce la aplicación estricta de las reglas sobre carga probatoria o la función preventiva del derecho de daños, contienen parcialmente su ámbito de aplicación, pero se muestran incapaces de diseñar una regla general sobre la pérdida de oportunidad que resuelva el problema de la causalidad en los casos siguientes:

a. Causalidad probabilística. No existe acuerdo sobre si la doctrina de la pérdida de oportunidad ha de limitarse exclusivamente a aquellos casos en que la oportunidad perdida sea inferior al umbral de certeza o si, por el contrario, ha de extenderse su aplicación a todos los casos, incluso a aquellos en que la probabilidad sea superior al estándar de persuasión y, por tanto, conforme a las reglas tradicionales sobre prueba permitiera la indemnización por los totales perjuicios sufridos por la víctima. Lo anterior no supone, sino la sustitución de la doctrina tradicional por una regla de causalidad proporcional, conforme a la cual el agente siempre será considerado causante del daño en función de la probabilidad estadística de su causación y condenado a pagar una indemnización acorde a dicha probabilidad.

Sin entrar en la discusión sobre la preferencia por unas u otras reglas de responsabilidad, un sector de la doctrina ha recurrido al criterio de las consideraciones sobre la regla de derecho aplicable a cada caso, como instrumento para contener la expansión de la doctrina. Así, cual sea el propósito de la norma vulnerada en cada caso ha de conducir al juzgador a aplicar o no dicha doctrina en orden a garantizar su cumplimiento. 
b. Probabilidades estadísticas muy reducidas. En segundo lugar, se ha planteado si debe imponerse un porcentaje a partir del cual sea posible obtener la reparación por las oportunidades perdidas. Con carácter general se asume en la jurisprudencia que la doctrina de la pérdida de oportunidad permite la indemnización de cualesquiera probabilidades estadísticas, incluso, aunque estas sean muy reducidas. Tan cuestionable es indemnizar con el 100\% a quien solo tenía un 95\% de probabilidades de supervivencia como indemnizar estas probabilidades estadísticas reducidas. No obstante, en estos casos el requisito causal se diluye y la indemnización de oportunidades muy reducidas lleva a condenar al médico por el mero incremento del riesgo de sufrir un daño para el paciente, acaso insignificante, lo que contradice los principios de la responsabilidad civil médico-sanitaria.

c. Reducción estadística de probabilidades de curación o de supervivencia. La tercera cuestión a valorar es si la doctrina de la pérdida de oportunidad resulta de la aplicación en los casos de mera reducción estadística de probabilidades de curación o de supervivencia en que el paciente no sufre daño alguno. Si se entiende que la oportunidad perdida tiene un valor por sí misma, entonces su indemnizabilidad sería independiente de que el paciente efectivamente hubiera sufrido algún tipo de daño. Sin embargo, con el beneficio de la retrospección, la oportunidad estadística perdida carecía de valor, en tanto que el paciente no requirió de ella para evitar el resultado adverso. En realidad, puede afirmarse que ni siquiera se trataba de una verdadera oportunidad: el paciente no puede alegar que perdió una oportunidad, de ser esta repuesta, el resultado no sería más favorable que el definitivamente alcanzado, por lo que no debería recibir compensación alguna.

Estrechamente ligada a la cuestión anterior, se ha planteado si deben indemnizarse las oportunidades perdidas de curación o de supervivencia cuando el daño final todavía no se ha producido y es incierto si se producirá 
en el futuro, lo que se conoce como Proportional Risk Recovery. En tales casos se indemniza, no la causación de un daño médico-sanitario, sino la exposición a un riesgo como consecuencia de la conducta médica negligente. No obstante, la aplicación de esta doctrina supone indemnizar a pacientes que jamás sufrirán daño alguno, lo que conduce a la sobrecompensación.

\section{Conclusiones}

En el presente trabajo hemos realizado un análisis de la carga de la prueba de la perdida de oportunidad en la responsabilidad civil médica en Colombia, con el fin de profundizar en un campo complejo como son las acciones judiciales derivadas de la responsabilidad civil médica, considerando la teoría de la perdida de oportunidad para el paciente como un factor que puede determinar una mala praxis, en tal sentido presentamos las siguientes conclusiones:

a. En este trabajo se considera la doctrina de la pérdida de oportunidad como una teoría de desarrollo doctrinal y jurisprudencial, aplicada en el campo de la responsabilidad médica, tanto civil como administrativa.

b. Es utilizada como instrumento de facilitación probatoria que interviene en aquellos procesos de responsabilidad médico-sanitaria en los que, conforme a las reglas tradicionales de prueba, no hubiera sido posible acreditar la relación de causalidad entre la negligencia médica y el daño sufrido por el paciente.

c. Que la perdida de oportunidad plantea la existencia de una probabilidad significativa de que el daño no se hubiera producido de haberse dado la conducta debida, que aquella negligencia privó al paciente de oportunidades de curación o supervivencia que han de ser indemnizadas. Así, la indemnización se corresponderá con la fracción de la totalidad de los perjuicios sufridos por la víctima, atribuible a las oportunidades de curación o supervivencia destruidas por la negligencia médica.

d. Se hace necesario contener el ámbito de aplicación de esta doctrina para evitar que su aplicación suponga la sustitución sistemática y arbitraria de las reglas tradicionales de la causalidad y su prueba. 
e. Se negará la reparación de la mera reducción estadística de probabilidades, así como la pérdida de oportunidad cuando la producción del daño dependa de eventos futuros.

f. La teoría de la perdida de oportunidad es una herramienta facilitadora, pero no reemplaza el deber o carga procesal de las partes en el proceso de probar los hechos que alegan, su onus probandi.

Con los elementos presentados concluimos este trabajo, en el cual hacemos un análisis de la carga de la prueba de la perdida de oportunidad en la responsabilidad civil médica en Colombia, comprendiendo diversas aristas, pues reconocemos que estamos sentados en un campo probatorio donde es difícil acreditar el nexo de causalidad entre el comportamiento médico negligente y el daño sufrido por el paciente, apareciendo dentro de ese lugar inhóspito la doctrina de la pérdida de oportunidad.

\section{Referencias}

Arango, M. L. (2002). Breve Aproximación a algunos aspectos de la responsabilidad penal médica (Tesis de grado). Bogotá, Colombia: Universidad Pontifica de Salamanca.

Constitución Política de Colombia [Const.] (1991). Artículo 49 [Titulo II]. 2da Ed. Legis

Consejo De Estado, Sección Tercera. (7 de octubre de 1999). Exp. 12655. [C.P. María Elena Giraldo].

Consejo De Estado, Sección Tercera. (15 de junio de 2000). Exp. 12548. [C.P. María Elena Giraldo].

Consejo De Estado, Sección Tercera. (17 de agosto de 2000). Exp. 12123, [C.P. Alier Eduardo Hernández].

Corte Suprema De Justicia, Sala De Casación Civil. (14 de octubre de 1959). [M.P. Hernando Morales].

Corte Suprema De Justicia, Sala De Casación Civil. (1 de febrero de 1993). Exp. 3532. [M.P. Carlos Esteban Jaramillo].

Consejo De Estado, Sección Tercera. (11 de abril de 2002). Exp. 13122. [C.P. Alier Eduardo Hernández].

Corte Suprema De Justicia, Sala De Casación Civil. (12 de septiembre de 1985) [M.P. Horacio Montoya Gil]. 
Corte Suprema De Justicia, Sala De Casación Civil (26 de noviembre de 1986). Exp.2423 [M.P. Héctor Gómez Uribe].

Costales, J. F. (1995). La responsabilidad Civil Sanitaria (Medica y enfermeria). Burgos: Alcodecoa SL.

Constitución Española [Const. Esp.] (1978). Constitución Política de España. Artículo 43. [Título I], España.

Facio, J. P. (1981). Responsabilidad Extracontractual. Bogota: Temis.

Feger, A. R. (2003). Apuntes sobre la responsabilidad profesional en el sector sanitario. Revista española de seguros: Publicación doctrinal de Derecho y Economía de los Seguros privados, (113), 119-132.

Fernández, M. L. (2008). La responsabilidad Médica: Problemas Actuales. Bogotá, Colombia: Grupo Editorial Ibañez.

Jaramillo, J. T. (2010). Tratado de Responsabilidad Civil (Vol. I). Bogotá, Colombia: Legis Editores SA.

Jaramillo, Carlos (2002). Responsabilidad Civil Médica. Colección de ensayos No. 8, editorial Pontificia Universidad Javeriana.

Larrañaga, P. (1996). El concepto de responsabilidad en la teoría del derecho contemporaneo. (Tesis doctoral). México DF, España: Universidad de Alicante.

Fundación Mapfre (2004). Manual del seguro de responsabilidad civil. Madrid, España: Mapfre.

Matamorros, L. L. (2003). El concepto de los daños punitivos o punitice damage. Estudios socio jurídicos, 5(001).

Cueto Pérez, M. (1997). Responsabilidad de la Administración en la asistencia sanitaria. Valencia, España: Gradia Litografia SL.

Restrepo, S. Y. (2008). Responsabilidad Civil Medica. Bogota, Colombia: Biblioteca Juridica Dike. 
